Schwebstoffen (wie Osteuropa) noch einer hohen Ozonbelastung (wie die USA). Eher scheint sich eine Abhängigkeit von der Sprache zu ergeben, in der die Fragen gestellt wurden. Es ist nicht ganz auszuschließen, daß in englischsprachigen Ländern nur deshalb die meisten Asthmatiker gefunden wurden, weil die Bezeichnungen für die Symptome den Menschen auf Englisch am ehesten einleuchten.

Auch bei der Rhinokonjunktivitis ergibt die Studie keine klaren Hinweise auf mögliche allgemeine Ursachen, obwohl die Unterschiede zwischen den einzelnen Ländern noch größer waren als beim Asthma. In den Ländern mit der höchsten Prävalenz (Nigeria, Paraguay, Malta und Hongkong) ist der Heuschnupfen dreißigmal häufiger als in den seltener betroffenen Regionen (neben Äthiopien, Indonesien vor allem Länder des ehemaligen Ostblocks).

Beim atopischen Ekzem liegen die Prävalenzen in Nigeria, Großbritannien, Finland, Schweden sogar 60fach höher als in China, Taiwan, Albanien und Georgien.

Einigermaßen konstant „schnitten "übrigens die beiden deutschen Zentren Greifswald und Münster ,ab“. Mit einer Häufigkeit von etwa $15 \%$ beim Asthma (Großbritannien bis 40\%, Indonesien unter $5 \%$ ), von etwa $15 \%$ bei der Rhinokonjunktivitis (Nigeria 40\%, Albanien unter 5\%) und etwa 7\% beim atopischen Ekzem (Nigeria 20\% und Albanien unter 1\%) liegt Deutschland weltweit im Mittelfeld. Auf den ersten Blick wurden zwischen Ost- und Westdeutschland keine wesentlichen Unterschiede festgestellt.

Eine nähere Auswertung der Ergebnisse steht noch aus. In der ersten Publikation im Lancet waren auf acht Seiten nur sehr allgemeine Angaben zu den einzelnen Ländern möglich. Global liegt die Prävalenz von Asthma unter 13-14jährigen bei $8 \%$. An einer allergischen Rhinokonjunktivitis litten 7,5\% der Altersgruppe, und bei 3,6\% der Kinder wurde die Verdachtsdiagnose atopisches Ekzem gestellt. Etwa 1,3\% der Kinder litten an allen drei Erkrankungen gleichzeitig.

Die Autoren um Richard Beasley von der Wellington Asthma Research Group aus Neuseeland schreiben zwar, daß die großen Unterschiede in den Häufigkeiten darauf hindeuten, daß „Umweltursachen (in ihrem weitesten Sinn) für die Entstehung dieser Erkrankungen bei Kindern von entscheidender Bedeutung sein könnten“. Für weitere Erkenntnisse verweisen sie jedoch auf die noch ausstehenden Einzelanalysen. Weitere Hinweise könnte die Auswertung der Befragung von Kindern während der Einschulung im Alter von 6 bis 7 Jahren bringen, die ebenfalls noch aussteht.

$\mathrm{Ob}$ die Untersuchung einmal die Bedeutung haben wird wie die Untersuchungen von Richard Doll zur Krebshäufigkeit in den 50er und 60er Jahren, wie die Autoren hoffen, bleibt abzuwarten. $\mathrm{Zu}$ vermuten ist, daß die Studie letzlich mehr Fragen aufwirft als beantwortet. Zum Beispiel: Warum erhöht eine Atopie das Risiko einer Asthmaerkrankung in den Industrieländern, während sie in Äthiopien eine protekti- ve Wirkung zu haben scheint? Warum differierten die Prävalenzen in Europa so viel stärker als in den vor wenigen Jahren in Westeuropa durchgeführten European Community Respiratory Health Surveys (ECRHS)?

Die Verfasserin des Editorials Sarah Lewis von der Universität Nottingham vermutet, daß sich ISAAC bald zu einem „Hypothesengenerator“ der Asthmaforschung entwickeln werde. Antworten sind von einer Fortsetzung von ISAAC $\mathrm{zu}$ erwarten. Für ISAAC-II sind erstmals objektive klinische Parameter wie Hauttests vorgesehen. Dennoch war ISAAC-I ein wichtiger erster Schritt zum besseren Verständnis atopischer Erkrankungen. Für viele Länder war es die erste epidemiologische Untersuchung zu diesem Thema. (rme)

Quellen: International Study of Asthma and Allergies in Child inood (ISSAC) Steering Conmittee: Worldwide variati(n) Junctivits and atopic Lancet 1998; 351: $1220-1$

\title{
Initialzünder für Asthma gefunden?
}

\section{Bei der Pathogenese des allergischen Asthmas scheinen die Gamma-Delta-T-Zellen eine entscheidende Bedeutung zu haben}

Eine Analyse der Bronchialflüssigkeit zeigte, daß die Mäuse ohne Gamma-Delta-T-Zellen die für die Entzündungsreaktion notwendigen Zytokine nicht produzieren. Der zu erwartende Anstieg von IL-5, IL-4 und Interferon blieb aus. Ebenso kam die Produktion der Antikörper IgE und IgG1 nicht in Gang. Wurde den Mäusen jedoch IL-4 injiziert, kam es wieder zu einer allergischen Reaktion. Dies bestätigt, daß dieses Zytokin eine wichtige Rolle im Immunprozeß der Allergie spielt. Es wird auch von verschiedenen anderen Zellen gebildet, beispielsweise den Mastzellen. Bei mastzellfreien Mäusen ist jedoch, im Gegensatz zu den Mäusen ohne Gamma-Delta-T-Zellen, eine Sensibilisierung weiterhin möglich.

(rme) Quelle: Zuany-Amorim C et al.: Requirement for gamma-delta
T Cells in Allergic Airway Inflammation. Science 1998; 280: 1265-7. 